\title{
Hiperfosfatasemia transitoria
}

\author{
Transient hyperphosphatasemia
}

\author{
Ariadne Fabiola Reyes Cortés, * Amador Pereira Díaz*
}

\section{Resumen}

La hiperfosfatasemia transitoria (HT) es una condición benigna y autolimitada en la que los niveles de fosfatasa alcalina (FA), en ausencia de otra enfermedad, se encuentran elevados. Su presentación es más frecuente en preescolares y escolares. El diagnóstico diferencial incluye enfermedades del hígado, riñón, hueso, intestino y sangre. En este reporte presentamos el caso de un paciente con hiperfosfatasemia transitoria y brindamos una revisión de la enfermedad, la cual es rara en la práctica clínica. El conocimiento de esta entidad disminuirá preocupaciones y abordajes innecesarios.

Palabras clave: Hiperfosfatasemia, transitoria, lactante.

\section{INTRODUCCIÓN}

Se define como hiperfosfatasemia a la elevación de los niveles séricos de fosfatasa alcalina. Esta condición se puede desarrollar en situaciones fisiológicas, tal como la pubertad; o en condiciones patológicas, como la enfermedad hepatobiliar, y de forma idiopática. En el grupo etario de lactantes y preescolares la causa más común es la hiperfosfatasemia benigna transitoria de la infancia. ${ }^{1}$

\section{CASO CLÍNICO}

Se trata de un niño de un año y tres meses de edad, sano, con el esquema de vacunación al corriente, sin antecedentes prenatales ni heredofamiliares de importancia y sin

\section{* Pediatra Neonatólogo.}

Hospital Ángeles Pedregal, Ciudad de México. México.

\section{Correspondencia:}

Ariadne Fabiola Reyes Cortés

Correo electrónico: ari_blume@hotmail.com

Aceptado: 21-08-2019.

www.medigraphic.com/actamedica

\section{Abstract}

Transient hyperphosphatasemia (TH) is a benign and selflimited condition in which serum levels of alkaline phosphatase (ALP) are elevated in the absence of other diseases. It is more frequent in children and infants. The differential diagnosis include liver, kidney, bone, intestinal and blood diseases. In this report we present one patient with transient hyperphosphatasemia and provide a review of this disease, which is rarely in clinical practice. The awareness of this condition will avoid unnecessary concerns and investigations.

Keywords: Hyperphosphatasemia, transient, infant.

hospitalizaciones previas. Su peso registrado fue de 11.860 $\mathrm{g}(\mathrm{p}+97)$, talla de $81 \mathrm{~cm}(\mathrm{p}+97), \mathrm{P} / \mathrm{T}$ p85. Presentó un cuadro enteral tratado con $5 \mathrm{~mL}$ de trimetoprim/sulfametoxazol cada ocho horas durante 10 días, completando cinco días de tratamiento.

Ingresó con un cuadro de 24 horas de evolución que se caracterizaba por evacuaciones disminuidas de consistencia con moco y sangre (aproximadamente 10), asociadas con fiebre mayor a $38.5^{\circ} \mathrm{C}$. A su ingreso al Servicio de Urgencias arribó con datos de deshidratación moderada. Se tomó biometría hemática, química sanguínea, electrolitos y panel gastrointestinal. El resultado fue positivo para Campylobacter y toxina A y B de Clostridium difficile. La fosfatasa alcalina de ingreso fue de 9,000 U/L; el resto de los exámenes de laboratorio, sin alteraciones. Durante su estancia se inició rehidratación, manejo sintomático de diarrea y antibiótico (vancomicina $1 \mathrm{mg} / \mathrm{kg} /$ dosis) cada seis horas por vía oral. El paciente presentó mejoría clínica, sin datos de alarma abdominal, con mejoría de la fiebre y de las características de las evacuaciones y con buena tolerancia de la vía enteral. Previo a su egreso se tomó de nuevo un control de fosfatasa alcalina, con reporte de 10,700 U/L, así como radiografía de huesos largos que se reportó como normal.

El paciente egresó de nuestra unidad a las 48 horas en buenas condiciones generales, con indicación de seguimiento como paciente externo. Se tomó un control al mes 
del egreso, que reportó los siguientes valores de FA: 978 $\mathrm{U} / \mathrm{L}, 25$-hidroxivitamina D: $35.8 \mathrm{ng} / \mathrm{mL}$, albúmina: $3.68 \mathrm{~g} /$ $\mathrm{dL}$, globulina: $3.14 \mathrm{~g} / \mathrm{dL}, \mathrm{TGP}: 27.4 \mathrm{U} / \mathrm{L}, \mathrm{TGO}: 37.7 \mathrm{U} / \mathrm{L}$, GGT: $12.9 \mathrm{U} / \mathrm{L}$. Su último control se realizó seis meses después del ingreso, cuyos valores de fosfatasa alcalina fueron de $355 \mathrm{U} / \mathrm{L}$ (Tabla 1).

\section{DISCUSIÓN}

La fosfatasa alcalina (FA) se produce principalmente en los huesos (85\%) y el hígado (15\%), aunque también en el intestino y la placenta. La actividad de la fosfatasa alcalina varía durante la vida, asociada con un incremento en la actividad osteoblástica de tres a cuatro veces por arriba de los límites durante la pubertad. ${ }^{2}$ Las causas de hiperfosfatasemia pueden variar desde condiciones patológicas hasta condiciones idiopáticas y fisiológicas. ${ }^{1}$

La hiperfosfatasemia benigna transitoria de la infancia fue descrita en 1954 por Bach, y sus criterios diagnósticos se establecieron en 1985 por Kraut y otros (Tabla 2). ${ }^{3,4} \mathrm{Su}$ prevalencia es difícil de estimar, dado que suele ser un hallazgo incidental.5, 6 Pese a ello, algunas series la reportaron entre 1.5 a $5.1 \%$ durante la infancia. ${ }^{7-10}$

Esta entidad benigna se caracteriza por elevaciones entre los valores normales de fosfatasa alcalina de cuatro a 50 veces en niños menores de cinco años, en ausencia de enfermedad ósea o hepática, siendo mas común entre los dos y los 18 meses. ${ }^{8,11}$

La etiología es multifactorial; las infecciones respiratorias y gastrointestinales parecen ser factores desencadenantes en la mayoría de los pacientes, como en el caso que reportamos. 9,11,12, También se ha asociado con uso de medicamentos como trimetoprim/sulfametoxazol, ciclosporina A, albúmina y algunos anticonvulsivantes. ${ }^{8,9}$ Se observa también un pico estacional durante las épocas de otoño e invierno. ${ }^{9,13}$ La duración está relacionada con los ciclos de reabsorción ósea, que es aproximadamente de cuatro meses, ${ }^{11}$ con un rango de entre dos semanas hasta cuatro años y una media de 10 semanas. $^{9}$

Nuestro reporte cuenta con limitaciones, dado que se trata de un caso aislado, además de sólo contar con una determinación de 25-hidroxivitamina D.

Tabla 1: Valores de hiperfosfatasemia transitoria desde la presentación y durante el seguimiento.

\begin{tabular}{lccc} 
& Ingreso & Un mes & Seis meses \\
\hline $\begin{array}{l}\text { Fosfatasa } \\
\text { alcalina }\end{array}$ & $10,700 \mathrm{U} / \mathrm{L}$ & $978 \mathrm{U} / \mathrm{L}$ & $355 \mathrm{U} / \mathrm{L}$ \\
& & & \\
\end{tabular}

Tabla 2: Criterios diagnósticos de hiperfosfatasemia benigna transitoria de la infancia.

Edad menor de cinco años

Sintomatología variable

Ausencia de signos clínicos de enfermedad ósea y/o hepática ${ }^{a}$ Ausencia de signos bioquímicos de enfermedad ósea y/o hepáticab $^{\mathrm{b}}$

Ausencia de signos bioquímicos de enfermedad ósea y/o hepáticab

Normalización en un plazo igual o inferior a cuatro meses

a Signos clínicos de enfermedad ósea: deformidades esqueléticas, mal incremento estatural, fracturas patológicas o dolores óseos; signos clínicos de enfermedad hepática: ictericia, coluria, acolia, visceromegalias. ${ }^{b}$ Signos bioquímicos de enfermedad ósea: alteración de los niveles de calcio, fósforo, 25-OH vitamina D3 y hormona paratiroidea; signos bioquímicos de enfermedad hepática: elevación de enzimas hepáticas

Fuente: Kraut et al. ${ }^{4}$

\section{CONCLUSIÓN}

La hiperfosfatasemia transitoria es una entidad autolimitada y benigna. El diagnóstico se basa en la normalización de sus valores, en ausencia de evidencia de la enfermedad hepática u ósea. La consideración de esta entidad en el contexto antes mencionado es de vital importancia tanto para la orientación para los padres como para el manejo conservador de esta condición.

\section{REFERENCIAS}

1. Schonhaut $\mathrm{L}$, Rocha A. Benign transient hyperphosphatasemia in infants, clinical series. Rev Chil Pediatr. 2017; 88 (1): 176-181.

2. Cho SM, Lee SG, Kim HS, Kim JH. Establishing pediatric reference intervals for 13 biochemical analytes derived from normal subjects in a pediatric endocrinology clinic in Korea. Clin Biochem. 2014; 47 (18): 268-271.

3. Bach U. Das verhalten der alkalischen serum- phosphatase bei Frughgerborenen. Rachitikern und Spasmophilen. Z Kinderheilk. 1954; 74: 593-609.

4. Kraut JR, Metrick M, Maxwell NR, Kaplan MM. Isoenzyme studies in transiente hyperphosphatasemia of infancy, in new cases and review of the literature. Am J Dis Child. 1985; 139 (7): 736-740.

5. Eymann A, Cacchiarelli N, Alonso G, Llera J. Benign transient hyperphosphatasemia of infancy. A common benign scenario, a big concern for a pediatrician. J Pediatr Endocrinol Metab. 2010; 23 (9): 927-30.

6. Behúlová D, Bzduch V, Holesova D, Vasilenkova A, Ponec J. Transient hyperphosphatasemia of infancy and childhood: Study of 194 cases. Clin Chem. 2000; 46 (11): 1868-1869.

7. Teitelbaum JE, Laskowski A, Barrows FP. Benign transient hyperphosphatasemia in infants and children: a prospective cohort. J Pediatr Endocrinol Metab. 2011; 24 (1-2): 351-353. 
8. Otero JL, González-Peralta RP, Andres JM, Jolley CD, Novak DA, Haafiz A. Elevated alkaline phosphatase in children: An algorithm to determine when a "Wait and See" approach is optimal. Clin Med Insights Pediatr. 2011; 5: 15-18.

9. Gualco G, Lava SA, Garzoni L, Simonetti GD, Bettinelli A, Milani G et al. Transient benign hyperphophatasemia. J Pediatr Gastroenterol Nutr. 2013; 57 (2): 167-71.

10. Lo SF. Reference Intervals for Laboratory Tests and Procedures. In: Behrman RE, Kliegman RM, Jenson HB, eds. Nelson Textbook of Pediatrics. 19th ed. Philadelphia: WB Saunders; 2011: 2466.
11. Kutilek S, Cervickova B, Bebova P Kmonickova M, Nemec V. Normal bone turnover in transient hyperphosphatasemia. J Clin Res Pediatr Endocrinol. 2012; 4 (3): 154-156.

12. Turan S, Topcu B, Gökçe I, Güran T, Atay Z, Omar A et al. Serum alkaline phosphatase levels in healthy children and evaluation of alkaline phosphatase z-scores in different types of rickets. J Clin Res Pediatr Endocrinol. 2011; 3 (1): 7-11.

13. Carroll AJ, Coakley JC. Transient hyperphosphatasaemia: an important condition to recognize. J Paediatr Child Health. 2001; 37: 359-62. 